\title{
The Polyethnolect Phenomenon in the current state of language in Germany and Russia
}

\section{[Феномен полиэтнолекта в современной языковой ситуации Германии и России]}

\author{
Nikolay Shamne - Marina V. Milovanova - Elena V. Terentyeva - \\ Irina M. Velibekova
}

\author{
DOI: 10.18355/XL.2016.09.04.46-57
}

\begin{abstract}
Аннотация
В данной статье на примере анализа языковой ситуации в Германии и России рассматриваются новые формы взаимодействия языков. Устанавливается общая тенденция к гибридизации устного общения в полиязычной среде, которая поразному реализуется в институциональном пространстве различных государств. В Германии названная тенденция представлена формированием полиэтнолекта как специфической формы обиходно-бытовой коммуникации в мультикультурном социуме; в России эта тенденция проявляется в активизации «Гибридных» лексем, образованных по русским словообразовательным и словоизменительным моделям и функционирующих преимущественно в сфере бытового общения. Авторы выделяют экстралингвистические и лингвистические факторы, существенно влияющие на появление новых трендов, детерминирующих изменения в современных языковых ситуациях.

Ключевые слова: языковая ситуация, миграция, языковые контакты, полиэтнолект, гибридные формы языка
\end{abstract}

\section{Введение}

Состояние естественного языка на всех этапах существования определяется характером воздействия на него совокупности экстралингвистических факторов, которые при определенных условиях способны угрожать стабильному функционированию языковой системы или, напротив, положительно влиять на нее.

К числу таких внелингвистических факторов, оказывающих существенное воздействие на состояние языка, традиционно относят рост/сокращение населения, рост/спад экономики, технологические, политические и экономические структуры, индивидуальное восприятие, потребности и т.п. (Haugen, 1972, 2001; Mackey, 1980, 2001; Fill, 2000; Finke, 2001; Halliday, 2001; Döring, 2005; Calvet, 2007; Шамне, Шовгенин, 2010). Названные обстоятельства существенно влияют на этнический континуум, детерминирующий характер языковой ситуации и языковое разнообразие в том или ином регионе.

Глобальные потрясения в экономике, мировые политические процессы, связанные с дестабилизацией социально-политических систем ряда государств, проблемы международной миграции населения создают новые риски для многих стран, их языков и культур.

Вызовы последнего времени таковы, что в уже сложившиеся полилингвальные языковые ситуации европейских государств "вплавляются" все новые языки, за которыми стоят свои культурные традиции, что влечет за 
собой изменение лингвогеографического ландшафта идиомов, взаимодействующих между собой в границах социума (Мечковская 2001).

Как известно, многоязычие в Европе является, скорее, правилом, чем исключением. Во многих социумах распространен более чем один язык и фиксируется ситуация многоязычия. Многоязычие в узком смысле означает владение двумя или более языками, где один доминантен, остальные второстепенны. При этом выбор того или иного языка индивидуумом зависит от многих факторов: социальной ситуации, партнера и отношений с ним, профессионального контекста, а также от используемого средства коммуникации (устная или письменная речь).

В широком смысле понятие «многоязычие» означает сосуществование нескольких языков или вариантов одного языка на одной территории. Понятие «вариант» является лингвистическим термином для обозначения реально существующих различных форм одного языка, которые выделяются на основе исторических, региональных (диалект), социальных и этнических (социолект, этнолект), функциональных (специальный язык) и возрастных (например, молодежный сленг) признаков.

Наряду с хорошо известными вариантами языков полиязычной ситуации в ряде европейских социумов складываются предпосылки для появления нового феномена, получившего название мультиэтнолект, или полиэтнолект (Wiese 2010). Данный феномен определяется как особый этнолект, формирующийся в поликультурном социуме преимущественно в среде мигрантов, выходцев из разных стран, и объединяющий обиходно-разговорные и жаргонные элементы из нескольких неблизкородственных языков.

Изучение полиэтнолектов как специфического явления современной языковой ситуации различных социумов связано с анализом языковой ситуации, языковых контактов, типов билингвизма, языковой интерференции, экологии языка принимающей культуры.

Актуальность обсуждаемой проблемы обусловлена следующими факторами:

- важностью проведения комплексного исследования, объединяющего знания в области социолингвистики, межкультурной коммуникации, контактологии, эколингвистики для описания феномена полиэтнолекта и смежных с ним явлений;

- недостаточной разработанностью аспекта взаимосвязи разноуровневых факторов, влияющих на формирование полиэтнолекта;

- отсутствием научно обоснованных методик фиксации и описания полиэтнолекта и смежных явлений;

- необходимостью сопоставительных исследований в данной области.

В качестве рабочей гипотезы выдвигается положение о том, что полиэтнолект как гибридный обиходно-разговорный язык, возникающий под влиянием мигрантской среды, состоящий из принимающего языка-основы и элементов различных этнических языков мигрантов с преобладанием жаргонизмов, может по-разному проявлять себя в условиях различных социумов и оказывать существенное влияние на язык принимающей культуры.

\section{Теоретическая база исследования: состояние изученности проблемы}

Проблема языкового поликультурного пространства стала предметом широкого обсуждения лишь к концу XX - началу XXI века.

В зарубежной лингвистике вопросы влияния языка мигрантов разной этнической принадлежности на язык принимающей культуры рассматривают 
Л. Айхингер, П. Ауер, Н. Беренд, Х. Визе, А. Депперман, И. Дирим, И. Кайм, К. Менг, Р. Райтмайр и др.

В России ценные теоретические положения, затрагивающие различные аспекты взаимодействия языков, находят отражение в работах О.С.Ахмановой, Л.П.Крысина, Л.А.Ильиной, Ю.Д. Дешериева А.Е. Карлинского, Г.А. Климова, Г.П. Нещименко А.К. Матвеева, Н.Л. Шамне, А.Н. Шовгенина.

Изучение полиэтнолекта и близких к нему явлений тесно связано с проблемами экологии языка (термин Э. Хаугена), языковой вариативности и отчасти рассматриваются в работах О.В. Байковой, Н.Л. Шамне, А.Н. Шовгенина, М.В. Миловановой, Е.В. Терентьевой, В.И. Шляхова.

Исследование полиэтнолекта как специфического явления современной языковой ситуации опирается на комплексный подход, в рамках которого интегрируются знания в области социолингвистики, межкультурной коммуникации, контактологии. В настоящее время сходные проблемы активно разрабатывают в Институте немецкого языка в Мангейме К. Менг, Н. Беренд, A. Депперманн, в Лейпцигском университете X. Вицлак-Макаревич, в Потсдамском университете Х. Визе (Германия), в Хельсинском университете Е. Протасова (Финляндия), в Мичиганском университете К. Майерс-Скоттон (США).

\section{Методологические основы и методы исследования}

Методологическим основами изучения специфических разновидностей языка на территориях, где взаимодействуют различные этносы, являются положения об отражении в языке социума окружающей действительности (В. фон Гумбольдт, Э. Сепир, Л. Вайсгербер, А. Вежбицкая), формировании коммуникативной компетенции индивида на основе его социального и национально-культурного опыта (В.И. Карасик, Ю.Н. Караулов, Н.Л. Шамне).

Кроме того, учитываются достижения социологии, в частности, основные положения теории ассимилятивных процессов, разработанной немецкими социологами. Под ассимиляцией понимается «процесс приспособления поведения индивидуумов и коллективов к институционализированным социальным установкам» принимающего общества (Bade/Bommes, 2004: 9). X. Эссер выделяет четыре аспекта ассимиляции: культурный (изучение языка), структурный (изучение профессии и возможность предложения услуг на рынке труда), социальный (контакт с принимающим обществом и вступление в брак с членами данного общества) и эмоциональный (идентификация поведения с поведением принимающего общества). Структурная ассимиляция, по мнению ученого, является для мигрантов необходимой в целях обеспечения экономической состоятельности. Культурный и социальный аспекты также играют немаловажную роль и состоят в тесной связи со структурной ассимиляцией (Esser, 2004).

Социологи К. Баде и М. Боммес описывают ассимиляцию как многосторонний процесс, в котором индивидуумы обладают правом участия во всех необходимых для жизни сферах общественной деятельности. Степень участия зависит от моральных ресурсов, материальных средств, от социальных отношений мигрантов, с одной стороны, и от социальных условий, действующих в различных сферах общества, необходимых для жизнеобеспечения мигрантов. Ученые подчеркивают, что процесс ассимиляции напрямую зависит от готовности принимающего общества к содействию мигрантам в сфере образования и трудоустройства. Таким образом, процесс ассимиляции является общей для мигрантов и принимающего общества задачей (Bommes, 1993).

48

XLinguae Journal, Volume 9 Issue 4, October 2016, ISSN 1337-8384 
Исходя из готовности мигрантов к ассимиляции, целесообразно выделить две группы: мигрантов первого поколения и мигрантов второго и последующего поколений. Мигрантам первого поколения присущ так называемый «менталитет рабочего», который характеризуется: неброским поведением в обществе, умеренным контактом с местными жителями, сохранением традиционных ценностей и т.д. Представители первого поколения, не желая терять идентичность, соблюдают дистанцию с местными жителями, объединяются в этнические группы, поэтому, как правило, изучают язык исключительно в бытовых условиях.

Иначе обстоит дело с мигрантами второго и третьего поколений, обладающих иным самосознанием. Их социализация протекает на фоне взаимодействия двух языков и культур. Именно таким образом они соединяют элементы обоих культур в своем мышлении, языке и поведении. Представители данного типа позитивно относятся к владению двумя или более языками и воспринимают это как расширение и обогащение их мыслительного и деятельностного пространства. Они идентифицируют себя как часть общества, не забывая при этом о своей родной культуре (Dirim/Auer, 2004).

Полиэтническое языковое пространство является предпосылкой развития новых языковых и коммуникативных форм: Code-switching (переключение языковых кодов), Code-mixing (смешение языковых кодов) и этнолектов. Codeswitching и Code-mixing являются распространенными практиками среди индивидуумов, владеющих двумя или более языками (Шамне, 2014: 65-67). Этнолекты возникают в многоязычных группах (в школе, центрах), когда родной язык участников не совпадает, поэтому они вынуждены выбрать средство общения, более или менее понятное для всех участников коммуникации.

Возникновение новых форм языкового взаимодействия в социуме требует использования специальных методик, нацеленных на сбор и анализ фактического материала. В рамках изучения феномена полиэтнолекта применялся лингвистический мониторинг, опирающийся на разработанные теоретические основы эколингвистического мониторинга языка региона (Шамне, Шовгенин, 2010).

Лингвистический мониторинг включает следующие этапы:

- этап фиксации изменений в языке (например, изменения на лексическом, фонетическом, грамматическом уровне, а также в использовании языка);

- этап установления действующей силы изменений (рост/сокращение населения, состояние экономики и т.д.);

- этап воздействие возникших изменений (например, рост/понижение уровня образования, потребности, престижное социальное поведение и т.п.);

- этап разработки возможных мероприятий для баланса межъязыкового взаимодействия (например, правовое регулирование, социальное воздействие на восприятие статуса происходящих изменений).

В результате устанавливаются количества и качества изменений в языке, результирующих из зависимости между действующей силой изменений в языке и последствиями ее воздействия на язык, а также в определении характера реагирования на происходящие изменения.

Таким образом, алгоритм выполнения исследовательских мероприятий мониторинга включает сбор и обработку данных для внесоциальных, социальных, лингвистических и социолингвистических переменных. 
Для решения задач исследования применяются также методы наблюдения, опроса, анкетирования, интервьюирования, что позволяет получить достоверный фактический материал.

Лингвистический аспект исследования предполагает использование сопоставительного анализа различных составляющих современной языковой ситуации, а также анализ интерферентных явлений в речи мигрантов, обусловленных взаимодействием элементов родного языка и языка принимающей культуры.

\section{Полиэтнолект как факт обиходно-разговорной коммуникации в Германии}

Трудовая миграция в Германии имеет длительную историю. В XVIIXVIII вв. мигранты из Европы (Франции, Нидерландов, Бельгии) были задействованы в строительной, текстильной и оружейной промышленности, а в XIX веке граждане Польши, России, Сербии, Хорватии трудоустраивались в сфере горной, сталелитейной и дорожно-строительной сферах производства. Таким образом, история Германии, как и многих других европейских государств, связана с постоянными миграционными процессами, что позволяет говорить об их полиэтничности, поликультурности и многоязычии.

При образовании национального государства в XIX веке как новой формы общественного и политического правопорядка девиз «один народ, одно государство, один язык» до конца ХХ в. определял политическую деятельность Германии. Именно поэтому региональным вариантам языка, диалектам, а также языкам меньшинств не уделялось должного внимания.

Вместе с тем в 50-е гг. на фоне восстановления и роста экономики в Германии наблюдалась нехватка рабочей силы, вследствие чего в страну привлекались рабочие из Италии, Греции и Испании. В 60-х годах Германия вновь была вынуждена прибегнуть к привлечению иностранной рабочей силы, что обусловило приток мигрантов из Турции, Португалии и Югославии. В период улучшения конъюнктуры рынка (с 1967 года) в страну приезжали преимущественно мигранты из Турции.

С середины 70-х гг. ситуация в миграционной политике существенно изменилась. В период экономического спада в 1973 году правительство Германии было вынуждено ввести запрет на привлечение в Германию рабочей силы из стран, не входящих в Европейское экономическое сообщество. При этом мигранты имели право лишь на временное проживание в стране и периодически возвращались на родину. Однако уже и тогда некоторые турки с семьями и детьми все же смогли осесть в Германии в связи со сложной экономической ситуацией в Турции.

Таким образом, с середины 50-х гг. до 1973 г. (до начала действия запрета на привлечение в Германию иностранной рабочей силы) число мигрантов в стране достигло 14 млн. человек. К концу $80-$ х гг. число мигрантов составляло $7,7 \%$ от общего числа населения страны, к концу $90-х$ гг. - 9\%, что составляло 15,5 млн. человек (Keim, 2012: 34). Уже к середине 70-х гг. в больших городах Германии образовывались этнические жилые районы, состоящие из семей турецких мигрантов. К настоящему времени в Германии мигранты составляют около $19 \%$ от общего числа населения.

Несмотря на то, что история Германии долгие годы была связана миграционными процессами, лишь 1 января 2005 года вступил в силу Закон об иммиграции (Zuwanderungsgesetz), который урегулировал процесс миграции и способствовал содействию интеграции мигрантов. Как отмечают М. Баде и Й. Ольтмер, с опозданием в 40 лет миграционные процессы в стране были урегулированы на политическом и законодательном уровнях (Bade/Oltmer, 2003: 
169). Впервые правительством Германии были затронуты проблемы интеграции и адаптации мигрантов, их социального обеспечения, доступа к образовательным ресурсам и профессиональным возможностям, а также предложены и реализованы меры по улучшению условий жизни на институциональном и организационном уровнях. На сегодняшний день прибывшие когда-то в качестве «гастарбайтеров» мигранты турецкого происхождения проживают в Германии уже 40-50 лет; здесь родились, выросли и создали свои семьи их дети.

Очевидно, что длительная история миграции в Германии не могла не отразиться на немецком языке.

Как отмечалось выше, язык мигрантов первого поколения весьма скуден, используется лишь в бытовом общении и характеризуется в основном явлениями языковой интерференции: адаптацией к родному языку на грамматическом уровне (неиспользование артиклей, глагольных связок, упрощение падежной, родовой систем).

В качестве закономерных особенностей полиэтнического языкового пространства мигрантов второго и последующих поколений можно выделить следующие отличия:

- в бытовом домашнем, как правило, устном общении, дети изучают языки или диалекты регионов, откуда мигрировали их родители. В большинстве случаев родной язык мигрантов не изучается в образовательных учреждениях, следовательно, дети не владеют им в совершенстве;

- в образовательных учреждениях Германии мигранты знакомятся как с разговорным региональным вариантом немецкого языка, так и с литературным немецким языком, что дает возможность овладеть навыками устной и письменной речи;

- в повседневном общении и в контакте со сверстниками мигранты знакомятся с региональными вариантами языка, например, баварским или швабским и, в свою очередь, в процессе общения обеспечивают возможность для заимствований местным населением элементов своего языка;

- «немецкий гастарбайтера» (Gastarbeiterdeutsch), как правило, не используется в домашней коммуникации, за исключением, например, ситуаций общения родителей с местными жителями или с учителем. При этом дети четко осознают низкий уровень владения родителей немецким языком.

Таким образом, нельзя не отметить, что в процессе миграции в Германии и контакта языка принимающего общества с языками мигрантов в немецком языке появились и закрепились некоторые иноязычные элементы. Для обозначения новых форм в немецком языке, появившихся в последние годы вследствие миграции, используются такие понятия, как «Türkendeutsch» («немецкий турков»), «Kanak Sprak» («канакский язык»), «Kiezsprache» («немецкий для района»).

Как отмечает $\mathrm{X}$. Визе, в жилых районах с высокой долей мигрантов наблюдается активное функционирование некоторых слов или выражений, заимствованных в немецкий язык из турецкого или арабского языков. Данная тенденция характерна преимущественно для молодежного жаргона вследствие тесного контакта местного немецкоязычного населения с мигрантами. Автор подчеркивает, что в берлинском районе Кройцберг на «Kiezdeutsch» разговаривают многие из живущих там немцев.

В качестве примеров ученый приводит такие слова, как Lan (дословно «человек/тип») и wallah (дословно «Аллах»). Эти заимствования не являются признаком смешения турецкого и немецкого или арабского и немецкого языков, напротив, данные слова интегрированы в немецкий язык, адаптированы к 
правилам грамматики и фонетики немецкого языка. Так, слово Lan принимает грамматические формы существительного das Alter (разг.: старина), а слово wallah - формы наречия echt (действительно/точно). Х. Визе сравнивает употребление вышеприведенных слов с употреблением слова Computer, тем самым подчеркивая достаточно высокую частотность их употребления в коммуникации (Wiese, 2010).

Еще одной особенностью обиходно-разговорной коммуникации, функционирующий в зоне языкового контакта поликультур, является гибридизация, то есть смешение форм немецкого и турецкого языков. Как правило, такие слова образуются путем слияния немецкого слова и созвучной ему характерной для турецкого языка формой на “m”. В качестве примеров можно привести слова Colamola (нем.: Cola, pyc.: кола) и Fahrradmahrrad (нем.: das Fahrrad, рус.: велосипед).

Таким образом, можно констатировать факт активного взаимодействия этнолектов в Германии. Явления полиэтнолекта обнаруживаются и в языке мигрантов, и в языке немецкоязычного населения.

\section{Процессы гибридизации в русском языке как результат взаимодействия этнолектов в полиязычном пространстве}

Русский язык в силу целого ряда причин в течение многих веков функционирует как средство межнационального общения, он находится в постоянном взаимодействии с другими языками как внутри Российской Федерации, так и за ее пределами. Условия для контактирования русского языка c различными разноструктурными этническими языками значительно расширились в последние двадцать лет в связи с активизацией миграционных процессов. Как следует из отчетов Росстата, число мигрантов в современной России достигает 11 млн. человек, что составляет около $8 \%$ от всего населения страны. При этом следует отметить, что миграционные потоки в России также распределяются неравномерно: наибольший приток мигрантов отмечается в Центральном, Северо-Западном, Южном и Дальневосточном федеральных округах. Так, например, с начала 2000-х годов на субъекты Российской Федерации, входящие в состав Южного федерального округа, в последние годы приходилось до $15 \%$ общероссийского миграционного прироста 'Игнатова, Николенко, 2011: 44).

Ощутимый поток мигрантов, прибывших в Российскую Федерацию в период с 2000 по 2015 гг. и привнесших в языковую среду современной России различные языки и культуры, безусловно, повлиял русский язык, что обусловило появление исследований состояния русского языка с позиций эколингвистики.

Эколингвистика как научное направление в изучении языковой сферы обитания человека и общества фокусируется на выявлении законов, принципов и правил, общих как для экологии, так и для развития языка (Haugen 2001). Центральный объект эколингвистики - взаимодействие языка со средой следует понимать как двуединый процесс: внешняя среда через человека, социум воздействует на язык, а язык как центральный компонент психосферы человека влияет на социум в целом и индивида, на нравственный и духовный уровень общества определенного времени. Практически любой регион современной России является многоязычным, имеющим в своей структуре представителей различных диаспор. Каждая диаспора, в свою очередь, вовлечена в коммуникативное взаимодействие с языковым большинством (Шамне, 2011). Такая ситуация, характеризующаяся неравноценным, но обоюдным влиянием языков, рождает очевидную необходимость осмысления 
этого взаимодействия в связи с изучением функционирования русского языка в полиэтнической среде (Милованова, Терентьева, 2013). В специальной литературе обсуждаются также проблемы лингвокультурной и социальной адаптации мигрантов в полиэтническое пространство различных регионов России, предлагаются разнообразные методики обучения русскому языку для различных групп мигрантов (Шамне, 2012, 2013; Милованова, 2012).

Осуществление эколингвистического мониторинга языка региона на примере Волгоградской области без отнесения полученных результатов к «здоровым» либо «нездоровым» проявлениям языкового употребления, показал, что пока преждевременно говорить о распространения полиэтнолекта в русскоязычной среде. Проведенные исследования, ограниченные рамками отдельных регионов, позволяют сегодня обобщить некоторые наблюдения над устной русской речью там, где миграционные процессы или языковые контакты особенно активны.

Предваряя обсуждение конкретных языковых фактов, выскажем некоторые общие соображения.

Россия с начала своего сосуществования складывалась как многонациональное государство. Русский язык находился в постоянном контакте с другими языками, что само по себе было условиям для толерантного отношения к языкам и заимствованиям из них, создавало, выражаясь формулой Э. Сепира, «психологическую установку самого языка» на открытость к различным языкам и культурам (Сепир, 2003). Такая открытость обогащала не только словарный запас языка, но и культурный потенциал народа. И хотя тезис о том, что одни языки в силу своего строения или других особенностей более восприимчивы к заимствованиям, чем другие, как отмечает Э. Хауген, остается пока не доказанным, все же высокая толерантность к заимствованиям русского языка общеизвестна. Данный факт свидетельствует об открытости русской культуры к культурам других народов, ее способности обогащаться в процессе постоянного культурного взаимодействия. Иноязычные слова довольно легко адаптируются к фонологической системе русского языка, обрастают грамматическими формами, включаются в словообразовательные ряды и перестают ощущаться чужими. Сегодня мало кто из носителей русского языка считает нерусским слово компьютер, несмотря на то, что в устной речи отмечаются произносительные варианты (компью[т]ер и компью[т']ер), свидетельствующие об иноязычном происхождении слова.

Однако процесс заимствований новых слов, при котором слово в целом сохраняет облик языка-источника, необходимо отличать от слов-гибридов, приобретающих черты двух языков. Такие гибридные образования активно появляются в условиях тесных бытовых, социальных или профессиональных контактов.

В речи русскоязычного населения (преимущественно молодежи и людей активного трудоспособного возраста), контактирующего с представителями различных этнических групп мигрантов, отмечаются «гибридные» употребления, созданные по русским словообразовательным и словоизменительным моделям.

Появление мигрантов из Китая, Таджикистана способствовало возникновению в речи русскоязычной молодежи таких гибридных слов и устойчивых сочетаний, как нихаушки (приветик) от кит. 你好 nǐhăо (привет), чифанить (есть, насыщаться) от кит. 吃饭 chīfàn (потреблять пищу, буквально рис), однокоренное чифанька (небольшое кафе преимущественно китайской кухни); бросать гапьl - разговаривать (от таджикского гап - слово, речь, 
разговор). Большинство из этих слов оцениваются носителями языка как жаргонные.

Приведенные и аналогичные им примеры схожи с многочисленными гибридными формами, появившимися в разное время в молодежном жаргоне под влиянием английского языка: океюшки, лайкать, забанить, флудить, лагать, копипастить (из двух слов), креза, крезанутый, герла. Эти языковые факты легко укладываются в общую тенденцию гибридизации устной речи в рамках молодежного или профессионального общения. При этом, на наш взгляд, вряд ли стоит ожидать появления в русском языке на фоне усиления миграционных потоков неких новых форм, аналогичных «Türkendeutsch». Однако гибридные слова легко проникают на страницы печатных и электронных средств массовой информации, например: Чифанька (чефанька, чуфанька и даже чуханька) - это заведение общепита, часто нелегальное и подпольное, в котором подаются блюда китайской кухни. Слово «чифанька» произошло от китайского слова chifan - «есть, питаться». В русском сленге часто употребляются глаголь «чуфанить, чуфариться». Кроме Иркутска, чифаньки существуют во Владивостоке, Новосибирске, Хабаровске и других городах (Издательский дом Восточная Сибирь, 2015).

Что же касается обиходной коммуникации в среде мигрантов и внутри национальных диаспор России, то она отражает общие практики переключения и смешения языковых кодов, характерные для индивидуумов, владеющих двумя или более языками.

\section{Выводы}

Анализ языкового взаимодействия на фоне миграционных потоков в Германии и Росси позволяет сделать некоторые предварительные выводы.

В качестве основной можно выделить тенденцию к гибридизации языка принимающего общества, однако характер реализации этой тенденции в силу различных экстралингвистических и лингвистических факторов в Германии и России отличается.

К экстралингвистическим факторам можно отнести особенности исторического развития, специфику языковой политики, экономические условия, социально-демографический состав/ландшафт, территориальные и временные характеристики. Среди лингвистических факторов следует назвать глубину языковой толерантности и особенности строения языков.

Исторически Россия складывалась как многонациональное и многоконфессиональное государство, языковая политика которого строилась на укреплении естественной объединяющей роли русского языка как языка межнационального общения при поддержке этнических языков. Национальные диаспоры, традиционно проживающие в России, никогда не изолировались от русскоязычного населения, что определяло их высокую русифицированность. В 90-х годах XX века в связи с распадом СССР Россия пережила отток национальных языков, а в начале XXI века начался процесс притока мигрантов, который носит территориально неравномерный и относительно растянутый во времени характер. По данным социологов, мигранты составляют около $8 \%$ от всего населения современной России.

По сравнению с ситуацией в России в Германии отмечается более высокий удельный вес мигрантов в общем составе населения (19\%). Кроме того, наблюдается преимущественное распределение потоков мигрантов в западной части Германии при интенсивном наплыве представителей иноязычных и инокультурных этносов за довольно непродолжительное время; доминирует 
анклавный принцип расселения. Меры, предусматривающие адаптацию и языковую интеграцию мигрантов, активно практикуются с 2005 года.

В русском языке отмечается гибридизация лексики, относящейся преимущественно к бытовой сфере; отдельные лексемы могут проникать в публицистические тексты.

В немецком языке фиксируются заимствования, адаптированные к правилам грамматики и фонетики, а также специфические гибридные употребления, которые образуются путем слияния немецкого и турецкого или арабского слова.

Анализ языковых ситуаций показывает, что в языковом пространстве мигрантов как в Германии, так и в России отмечаются заимствования, кальки, смешения, гибридные формы, характерные для коммуникации на родном языке в иноязычном окружении. При этом язык мигрантов Германии демонстрирует активное взаимодействие форм турецкого и немецкого или арабского и немецкого языков; явления полиэтнолекта проникают в обиходную речь немецкоязычного населения. В России внутри национальных диаспор также наблюдается взаимодействие национального и русского языков, однако говорить о формировании элементов полиэтнолекта как в речи мигрантов, так и в речи русскоязычного населения пока преждевременно.

\section{Заключение}

Завершая обзор некоторых трендов современной полиязычной среды, важно подчеркнуть, что гибридные языковые употребления возникают там, где пересекаются социальные интересы мигрантов и представителей принимающего общества. Общая тенденция к гибридизации устного общения в полиязычной среде имеет разные формы реализации в различных институциональных условиях

В Германии тенденция к гибридизации представлена формированием полиэтнолекта как специфической формы обиходно-бытовой коммуникации в мультикультурном социуме; в России эта тенденция проявляется в активизации «Гибридных» лексем, образованных по русским словообразовательным и словоизменительным моделям и функционирующих преимущественно в сфере бытового общения.

\section{Bibliograpic references}

IGNATOVA, YU.E. - NIKOLENKO, N.A. 2011. Vliyanie regional'nyh uslovij na adaptacionnye processy trudovyh migrantov (na primere Volgogradskoj oblasti) // Vestnik Volgogr. gos. un-ta. Ser. 7, Filosofiya. 2011. № 3 (15). S. 43-48. ISSN 1998-9946.

MECHKOVSKAYA, N.B. 2001. Obshchee yazykoznanie: Strukturnaya i social'naya tipologiya yazykov. M.

MILOVANOVA, M.V. Puti i sposoby uluchsheniya ehkologii russkogo yazyka v poliehtnicheskom regione // Vlast'. 2012. № 7. S. 45-48. ISSN 2071-5358.

MILOVANOVA, M.V. TERENT'EVA, E.V. 2011. YAzykovoe prostranstvo poliehtnicheskogo regiona: problemy ehkologii. Volgograd : VolGU, 2011. ISBN 978-5-9669-0940-6.

SEPIR, EH. 2003. Status lingvistiki kak nauki. In: YAzyki kak obraz mira. M.: SPb: Terra Fantastica. S. 131.

SHAMNE, N.L. - SHOVGENIN A.N. 2010. Teoreticheskie osnovy postroeniya algoritma ehkolingvisticheskogo monitoringa // Vestn. Volgogr. gos. un-ta. Ser. 2. YAzykoznanie. № 2 (12). S. 153-161. ISSN 1998-9911. 
SHAMNE, N.L. 2011. EHkolingvisticheskoe issledovanie yazykovogo prostranstva poliehtnicheskogo regiona // Izvestiya Volgogradskogo gosudarstvennogo pedagogicheskogo universiteta. № 8. T. 62. S. 143-146. ISSN 1815-9044.

SHAMNE, N.L. 2012. Razrabotka prognozov razvitiya russkogo literaturnogo yazyka v Nizhnevolzhskom regione // Vlast'. № 7. S. 165-168. ISSN 2071-5358.

SHAMNE, N.L. 2013. Kul'turno-yazykovaya i social'naya adaptaciya migrantov // Vlast'. № 6. S. 44-47. ISSN 2071-5358.

SHAMNE, N.L. 2014. Aktual'nye problemy mezhkul'turnoj kommunikacii : ucheb. posobie. Volgograd: VolGU. 200 s. ISBN 978-5-9669-1322-9.

BADE, K. - OLTMER, J. 2003. Zwischen Aus-und Einwanderungsland: Deutschland und die Migration seit der Mitte des 17. Jahrhunderts// Zeitschrift für Bevölkerungswissenschaft. № 2-4. S. 263-306.

BADE, K. - BOMMES, M. 2004. Migration - Integration - Bildung Grundfragen und Problembereiche. $204 \mathrm{~S}$.

BOMMES, M. 1993 Migration und Sprachverhalten: Eine Ethnographischsprachwissenschaftliche Fallstudie (DUV Sozialwissenschaft). Wiesbaden.

CALVET L.-J., 2007. Approche sociolinguistique de l'avenir du français dans le monde // Hérodote, № 3 (126). P. 153-160.

DIRIM, I. - AUER, P. 2004. Türkisch sprechen nicht nur die Türken, Berlin, 2004. $245 \mathrm{~S}$.

DÖRING, M. 2005. Wir sind der Deich: Zur metaphorisch-diskursiven Konstruktion von Natur und Nation. Hamburg: Verlag Dr. Kovac.

ESSER, H. 2004. Welche Alternativen zur „Assimilation“ gibt es eigentlich? // IMISBEITRÄGE. Heft 23. S. 41-60.

FILL, A. 2000. Language and Ecology: Ecolinguistic Perspectives for 2000 and Beyond. Tokyo. P. 162-176.

FINKE, P. 2001. Identity and Manifoldness: New Perspectives in Science, Language and Politics. In: The Ecolinguistics Reader: Language, Ecology and Environment. London, New York: Continuum. P. 84-90.

HALliDAY, M. A. K. 2001. New Ways of Meaning: The Challenge to Applied Linguistics In: The Ecolinguistics Reader: Language, Ecology and Environment. London, New York: Continuum. P. 175-202.

HAUGEN, E. 1972. The Ecology of Language // Haugen. E. The Ecology of Language: essays by Einar Haugen / Selected and Introduced by Anwar S. Dil. Stanford, California: Stanford University Press.

HAUGEN, E. 2001. The Ecology of Language In: The Ecolinguistics Reader: Language, Ecology and Environment. London, New York: Continuum. P. 57-66.

KEIM, I. 2012. Mehrsprachige Lebenswelten, Tübingen. 263 S.

MACKEY, W.F. 1980. The ecology of language shift // Sprachkontakt und Sprachkonflikt. Wiesbaden. P. 35-41.

MACKEY, W.F. 2001. The Ecology of Language Shift In: The Ecolinguistics Reader: Language, Ecology and Environment. London, New York: Continuum. P. 67-74.

WIESE, H. Kiezdeutsch - ein neuer Dialekt //Aus Politik und Zeitgeschichte. № 8. S. 33-38.

Words: 4193

Characters: 34065 (18,92 standard pages)

Prof. Nikolai Shamne, DrSc.

Institute for Philology and Cross-Cultural

Communication Volgograd State University

Prospect Universitetsky, 100 400062,

Volgograd 
Russia

shamnenl@gmail.com

Prof. Marina Milovanova, DrSc.

Department of Russian language and documentation science Institute for Philology and Cross-Cultural Communication

Volgograd State University Prospect Universitetsky, 100 400062, Volgograd Russia milovanovamv05@yandex.ru

Doc. Elena Terentyeva, DrSc.

Department of Russian language and documentation science Institute for Philology and Cross-Cultural Communication Volgograd State University Prospect Universitetsky, 100 400062, Volgograd Russia terentieva2008@yandex.ru

Irina Velibekova

Postgraduate of German Philology Institute for Philology and Cross-Cultural Communication Volgograd State University Prospect Universitetsky, 100 400062,

Volgograd

Russia

velibekovai@mail.ru 